\title{
CORRIGENDUM
}

\section{Discovery of one of Sir John Franklin's ships- CORRIGENDUM}

\section{William Barr}

DOI: http://dx.doi.org/10.1017/S0032247414000758 Published by Cambridge University Press 15 October 2014

We regret that there were a number of minor errors in the second paragraph of the recent publication (Barr 2014)

The corrected paragraph is reprinted here. In addition, Scott Yougblott should have been Scott Youngblut throughout.

The Victoria Strait Expedition encountered very heavy ice in its proposed search area to the northwest of King William Island and hence shifted its focus further south to the southeast corner of Queen Maud Gulf. On 1 September Scott Youngblut, a scientist with the Canadian Hydrographic Service took off by helicopter from the Sir Wilfrid Laurier and landed on a small island, deliberately unidentified as Hat Island, to the northwest of O'Reilly Island and south of the Royal Geographical
Society Islands. His aim was to establish a beacon and to determine its position by GPS in order to tie-in sounding traverses. In addition to the search for the Franklin ships the expedition also aimed at improving the hydrographic charts of the area. Since there were vacant seats on the helicopter, Doug Stenton, Director of Nunavut Heritage and Culture and Robert Park, a professor of Archaeology at the University of Waterloo, Ontario, joined Youngblut on the flight. On the island they and the helicopter pilot discovered a fork-shaped metal object, about $43 \mathrm{~cm}$ long, identified as part of a ship's davit and bearing the Royal Navy's broad arrow symbol, and a wooden hawse plug.

\section{Reference}

Barr, W T. Discovery of one of Sir John Franklin's ships. Polar Record pp. 107-108. 